Article

\title{
Investigation of Solvatomorphism and Its Photophysical Implications for Archetypal Trinuclear $\mathrm{Au}_{3}$ (1-Methylimidazolate) 3
}

\author{
Shengyang Guan ${ }^{1,2}$, David C. Mayer ${ }^{1}$, Christian Jandl ${ }^{1}$, Sebastian J. Weishäupl ${ }^{1}$, Angela Casini ${ }^{2}$ (D) \\ and Alexander Pöthig ${ }^{1, *}$ \\ 1 Catalysis Research Center \& Department of Chemistry, Technische Universität München, \\ Ernst-Otto-Fischer Str. 1, D-85748 Garching b. München, Germany; shengyang.guan@tum.de (S.G.); \\ david.mayer@tum.de (D.C.M.); christian.jandl@tum.de (C.J.); sebastian.weishaeupl@tum.de (S.J.W.) \\ 2 Department of Chemistry, Technische Universität München, Lichtenbergstr. 4, \\ D-85748 Garching b. München, Germany; angela.casini@tum.de \\ * Correspondence: alexander.poethig@tum.de
}

check for updates

Citation: Guan, S.; Mayer, D.C.; Jandl, C.; Weishäupl, S.J.; Casini, A.; Pöthig, A. Investigation of Solvatomorphism and Its Photophysical Implications for Archetypal Trinuclear $\mathrm{Au}_{3}$ (1-Methylimidazolate) ${ }_{3}$. Molecules 2021, 26, 4404. https://doi.org/ $10.3390 /$ molecules26154404

Academic Editors: Marco Baron, Cristina Tubaro and Andrea Biffis

Received: 30 June 2021

Accepted: 16 July 2021

Published: 22 July 2021

Publisher's Note: MDPI stays neutral with regard to jurisdictional claims in published maps and institutional affiliations.

Copyright: (c) 2021 by the authors. Licensee MDPI, Basel, Switzerland. This article is an open access article distributed under the terms and conditions of the Creative Commons Attribution (CC BY) license (https:/ / creativecommons.org/licenses/by/ $4.0 /)$.

\begin{abstract}
A new solvatomorph of [ $\left.\mathrm{Au}_{3}(1-\mathrm{Methylimidazolate})_{3}\right]\left(\mathrm{Au}_{3}(\mathrm{MeIm})_{3}\right)$ - the simplest congener of imidazolate-based $\mathrm{Au}(\mathrm{I})$ cyclic trinuclear complexes (CTCs) - has been identified and structurally characterized. Single-crystal X-ray diffraction revealed a dichloromethane solvate exhibiting remarkably short intermolecular Au . . Au distances (3.2190(7) A). This goes along with a dimer formation in the solid state, which is not observed in a previously reported solvent-free crystal structure. Hirshfeld analysis, in combination with density functional theory (DFT) calculations, indicates that the dimerization is generally driven by attractive aurophilic interactions, which are commonly associated with the luminescence properties of CTCs. Since $\mathrm{Au}_{3}(\mathrm{MeIm})_{3}$ has previously been reported to be emissive in the solid-state, we conducted a thorough photophysical study combined with phase analysis by means of powder X-ray diffraction (PXRD), to correctly attribute the photophysically active phase of the bulk material. Interestingly, all investigated powder samples accessed via different preparation methods can be assigned to the pristine solvent-free crystal structure, showing no aurophilic interactions. Finally, the observed strong thermochromism of the solid-state material was investigated by means of variable-temperature PXRD, ruling out a significant phase transition being responsible for the drastic change of the emission properties (hypsochromic shift from $710 \mathrm{~nm}$ to $510 \mathrm{~nm}$ ) when lowering the temperature down to $77 \mathrm{~K}$.
\end{abstract}

Keywords: cyclic trinuclear complex; photoluminescence; aurophilic interactions

\section{Introduction}

Cyclic trinuclear complexes (CTCs) featuring three coordinated metal atoms in the nine-membered planar or near planar rings, represent some of the simplest polynuclear metal clusters. Comprehensive synthetic, structural, theoretical, and photophysical studies have been performed on a variety of cyclic trinuclear complexes, featuring series of angular ditopic bridging ligands, including carbeniate, pyrazolate, imidazolate, and triazolate ligands [1-7]. CTCs have found various applications in the field of intermolecular M(I)-M(I) interactions [8,9], metalloaromaticity / $\pi$-acidity and basicity [10], luminescence [11-13] and supramolecular assembly [14-16]. (Figure 1B-D) Imidazolate-based CTCs are the least studied compared to those of carbeniate and pyrazolate, only four examples have been reported (Figure 1A). In the 90s, Burini, Wagner and coworkers reported the synthesis of $\mathrm{Au}_{3}$ imidazolate CTCs bearing methyl or benzyl substituents, while more recently Omary et al. achieved complexes of general formula tris $\left[\left(\mu_{2}-1\right.\right.$-ethylimidazolato- $\left.\left.\mathrm{N}^{3}, \mathrm{C}^{2}\right) \mathrm{Au}(\mathrm{I})\right]$ $\left(\mathrm{Au}_{3}(\mathrm{EtIm})_{3}\right)(\mathrm{Et}=$ ethyl $)[3,7,17]$. These complexes exhibit rich supramolecular chemistry having, e.g., fascinating luminescence properties in sandwich adducts of $\mathrm{Au}(\mathrm{I})$ imidazolate 
CTCs with $\mathrm{Ag}^{+}$and $\mathrm{Tl}^{+}$[6]. Very recently, CTCs were also shown to act as donors with a range of planar $\pi$-acceptors and exhibited exceptionally strong binding, which envisaged more complicated aromatic donor-acceptor supramolecular assembly(Figure 1C) [18,19]. Remarkably, Fujita et al. used the tris $\left[\left(\mu_{2}-1\right.\right.$-methylimidazolato- $\left.\left.\mathrm{N}^{3}, \mathrm{C}^{2}\right) \mathrm{Au}(\mathrm{I})\right]$ (abbreviated ' $\mathrm{Au}_{3}(\mathrm{MeIm})_{3}$ ' in the following, $\mathrm{Me}=$ methyl) and $\mathrm{Ag}^{+}$ions to form an unprecedented triple-decker ion cluster $\left(\mathrm{Au}_{3}-\mathrm{Ag}-\mathrm{Au}_{3}-\mathrm{Ag}-\mathrm{Au}_{3}\right)$ within a self-assembled cage (Figure 1D) [14-16].

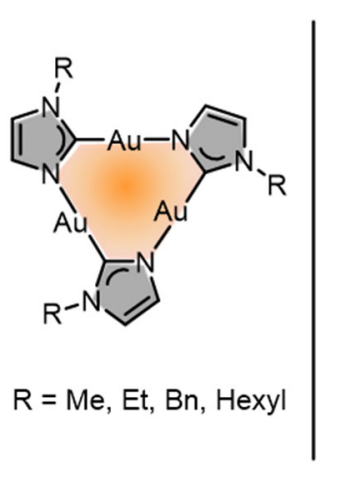

A

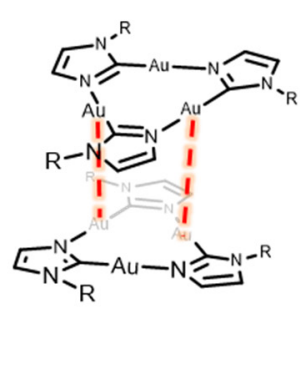

B

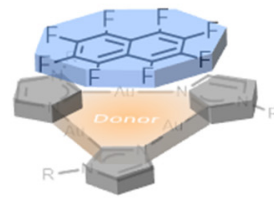

C

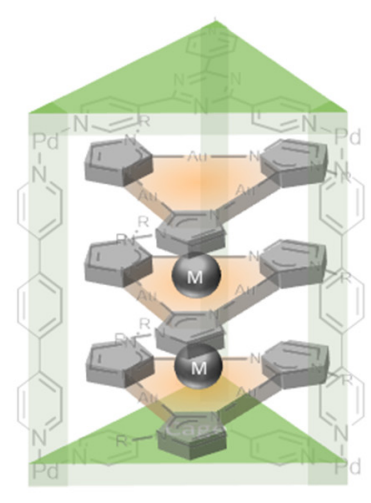

D

Figure 1. (A) General structure of imidazolate-based CTCs $\left[\mathrm{Au}_{3}(\mathrm{MeIm})\right]_{3}[7,20] ;\left[\mathrm{Au}_{3}\left(\mathrm{EtIm}_{3}\right]_{3}[3] ; \mathrm{Au}_{3}(\mathrm{BzIm})_{3}[19] ;\right.$ $\mathrm{Au}_{3}(\mathrm{HexIm})_{3}$ [18]; (B) illustration of possible metallophilic interaction (red dashed lines); (C) an example of $\pi$ electron lewis acid/base binding model [18]; (D) guest supramolecular trigonal prismatic arrays within a Pd(II) coordination cage host, $\mathrm{M}=\mathrm{Ag}^{+}$cation [14].

In this context, having great interest in small organometallic clusters [21,22], closedshell coinage-metal-based systems with fascinating photo-physical properties [23,24], we further consider the $\mathrm{Au}(\mathrm{I})$ imidazolate-type CTCs as a valuable platform to investigate the luminescence, inter- and intra-trimer metal-metal interactions and related supramolecular assembly. The simplest scaffold - $\mathrm{Au}_{3}(\mathrm{MeIm})_{3}$ was the first synthesized $\mathrm{Au}(\mathrm{I})$ imidazolate CTC by Burini in 1989 [7], but was not structurally determined until very recently by Ruiz et al. in 2020 [20]. The reported crystal structure showed no co-crystallization of solvent molecules or any pronounced intermolecular aurophilic interactions between $\mathrm{Au}_{3}(\mathrm{MeIm})_{3}$. When reinvestigating the synthesis, we serendipitously discovered a new solvatomorph at an unconventional cryogenic crystallization condition, which actually features a dimer formation of $\mathrm{Au}_{3}(\mathrm{MeIm})_{3}$ through aurophilic interactions. Such weak metallophilic interactions in linear-coordinate $\mathrm{Au}(\mathrm{I})$ complexes are similar to the energies of hydrogen bonds $[8,25]$, and are also involved in the occurrence of polymorphism/solvatomorphism in the solid-state [26-28]. In addition, aurophilic interactions are closely related to luminescence [29], pointing towards significant differences in the emission properties of the different solid-state structures. Therefore, we conducted a combined photophysical and structural study, accompanied by DFT-calculations, of $\mathrm{Au}_{3}(\mathrm{MeIm})_{3}$ being the archetypal molecule for imidazolate-based CTCs, to investigate which exact polymorph is the photophysically active phase.

\section{Results and Discussion}

We prepared $\mathrm{Au}_{3}(\mathrm{MeIm})_{3}$ mainly following the route described previously by Burini [7] and Vaughan [30] with minor modifications (see Experimental section for details). Numerous attempts have been made to obtain crystals suitable for single-crystal X-ray diffraction analysis, however, the majority of attempts were unsuccessful. For example, slow evaporation of a solution of $\mathrm{Au}_{3}(\mathrm{MeIm})_{3}$ in dichloromethane or chloroform solution at ambient conditions leads to the formation of a bright yellow solution and colloidal gold precipitation. To prevent decomposition, crystallization was then carried out at ultra-low temperature instead of reported room temperature crystallization. After keeping a saturated solution 
of dichloromethane/hexane (20:1) at $193 \mathrm{~K}\left(-80^{\circ} \mathrm{C}\right)$ for two weeks, colorless needle-like crystals suitable for a single-crystal X-ray diffraction (SC-XRD) study were obtained.

The SC-XRD result reveals the presence of a novel solvatomorph (hereafter referred to as the solvatomorph $\beta$ ) which is structurally different from the one previously reported (the structure discovered by Ruiz et al. is referred as the polymorph $\boldsymbol{\alpha}$ ) [20]. In detail, in solvatomorph $\beta$, the trinuclear complex $\mathrm{Au}_{3}(\mathrm{MeIm})_{3}$ crystallizes in triclinic system with space group $P-1$, featuring one co-crystallized solvent molecule of dichloromethane. The molecular structure of $\mathrm{Au}_{3}(\mathrm{MeIm})_{3}$ can be considered identical for solvatomorphs $\alpha$ and $\beta$, within the means of statistical errors. The three gold atoms are bridged by the three 1 methylimidazolates with each metal ion being bound to one nitrogen and one carbon donor atom from a neighboring imidazolate. The angles of N-Au-C slightly deviate from linearity, which is in agreement to previously reported $\mathrm{Au}_{3}$ imidazolium trimers featuring bulkier substituents (ethyl/benzyl) [3,17]. The distances of intramolecular contacts are slightly exceeding the range of reported $\mathrm{Au}_{3}$ imidazolium complexes (ethyl/benzyl) (3.436(2) to 3.465(3) A) [3,17].

Despite the similarities in the molecular structure, the packing of $\mathrm{Au}_{3}(\mathrm{MeIm})_{3}$ in solvatomorph $\beta$ is fundamentally different. The $\mathrm{Au}_{3}(\mathrm{MeIm})_{3}$ molecules show close contacts to one adjacent molecule, which can be attributed to attractive aurophilic interactions being absent in previously reported polymorph $\alpha$. As a result, two $\mathrm{Au}_{3}(\mathrm{MeIm})_{3}$ molecules are arranged in a twist-staggered fashion rotated by $180^{\circ}$ relative to each other. To further understand the attractive interactions between the trimeric molecules, Hirshfeld surface analysis [31] was applied for one $\mathrm{Au}_{3}(\mathrm{MeIm})_{3}$ molecule as shown in Figure 2B. In the $d_{\text {normal }}$ mapping, four pairwise equivalent interactions $(2 \& 3)$ on the Hirshfeld surface between two trimers can be observed, which we attribute to two aurophilic interactions (3) and two short contacts (2) between carbon atoms on the heterocyclic rings. The interactions 1 and 7 are related to solvent molecules. Hydrogen bonds $7(\mathrm{C}-\mathrm{Cl} \cdots \mathrm{H})$ are formed between imidazolate back-bone hydrogen atoms and chlorine atoms of dichloromethane. Interaction 1 (C-H ‥ Au distance: $2.7395 \AA$ ) resembles hydrogen bonds between dichloromethane and gold atoms, with $\mathrm{CH}$ group on dichloromethane acting as donor and gold acting as hydrogen bond acceptor. A survey using Cambridge Structural Database (CSD) was performed, revealing that among all the reported $\mathrm{Au}_{3}$ cyclotrimers preserving $\mathrm{Au} \cdots \mathrm{H}$ hydrogen bonding, $\mathrm{Au}_{3}(\mathrm{MeIm})_{3}$ has the shortest distance between hydrogen to the triangular centroid. The $\mathrm{Au} \cdots \mathrm{H}$ distance $(2.7395 \AA)$ is shorter than the sum of the van der Waals radii $(2.8 \AA$ ) [32]. In an authoritative review of the hydrogen bonding to gold, Schmidbaur et al. summarized different types of $\mathrm{Au} \cdot \mathrm{H}-\mathrm{X}$ bonding. In the discussion of $\mathrm{Au}_{3}$ or $\mathrm{Au}_{4}$ clusters, he concluded this kind of bonding is dominated by classical Lewisadduct formation [32-34]. Interactions $4 \sim 6$ are $\mathrm{CH} \cdots \mathrm{C}$ hydrogen bonds bridging the imidazolate back-bone hydrogen atoms to methylene groups of neighboured, symmetry equivalent dimers.

The related $\mathrm{Au}_{3}(\mathrm{EtIm})_{3}$ exhibits a similar stair-like dimer-trimer arrangement in the solid-state as solvatomorph $\beta$ (compare Figure 2C) [3]. To quantify this structural similarity, we defined three planes that go through the hexanuclear gold core in the dimer-trimer in Figure 2C. Plane $a$ is defined by Au1-Au2-Au3 on the top layer, plane $b$ is defined by Au1-Au3 on the top and Au1-Au3 on the bottom, the plane $c$ is defined by Au1-Au2-Au3 on the bottom. The plane angles $\angle a b$ and $\angle b c$ are both $88.07^{\circ}$ in $\beta$, smaller than the plane angles in $\mathrm{Au}_{3}(\mathrm{EtIm})_{3}$ (between 95.85 and $101.54^{\circ}$ ). The centroid $a$ and centroid $c$ are on parallel planes, their projections on the same plane are separated by $2.04 \AA$, while in the case of $\mathrm{Au}_{3}(\mathrm{EtIm})_{3}$, the distance is $2.00 \AA$ and $2.04 \AA$. The distance between plane $a$ and $b$ is shorter in $\mathrm{Au}_{3}(\mathrm{EtIm})_{3}$ compared to solvatomorph $\beta$ (3.01 $\AA$ vs. $3.18 \AA$ ), going along with shorter $\mathrm{Au}$-Au distances and stronger aurophilic interactions (3.066(1) \& 3.140(7) $\AA$ in $\left.\mathrm{Au}_{3}(\mathrm{EtIm})_{3}\right)$.

The differences between structure $\alpha$ and $\beta$ in the intermolecular interactions consequently lead to the aforementioned different packing of the two crystal structures as shown in Figure 3. $\mathrm{Au}_{3}(\mathrm{MeIm})_{3}$ molecules in the solvent-free monoclinic polymorph $\alpha$ are 
separated and form zigzag-like layers along the $c$ axis (Figure 3A). Hereby, the intermolecular interactions are dominated by hydrogen bonding, and the closest $\mathrm{Au}-\mathrm{Au}$ distance is 3.6660(5) $\AA$ [20]. In contrast, in the solvatomorph $\beta$, the dimers of $\mathrm{Au}_{3}(\mathrm{EtIm})_{3}$ are packed within layered arrangements in the $b-c$ plane (Figure $3 \mathrm{~B}$ ).

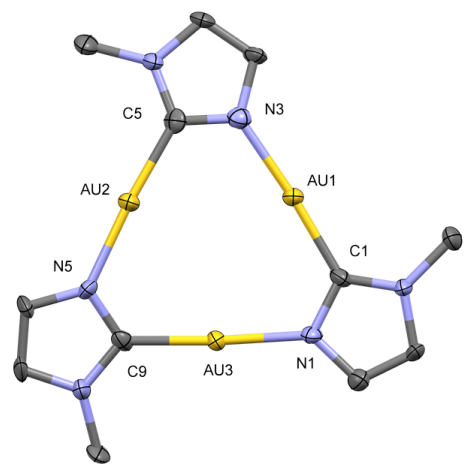

A

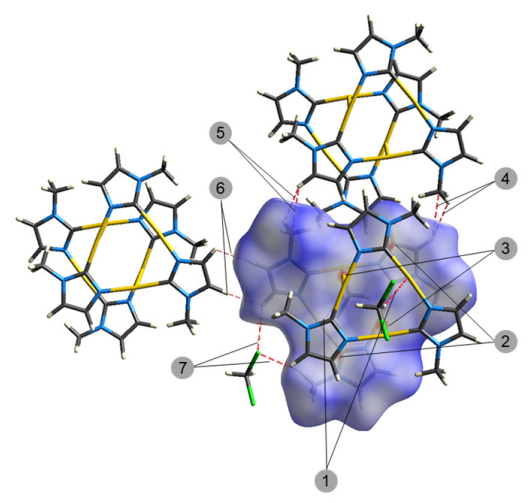

B

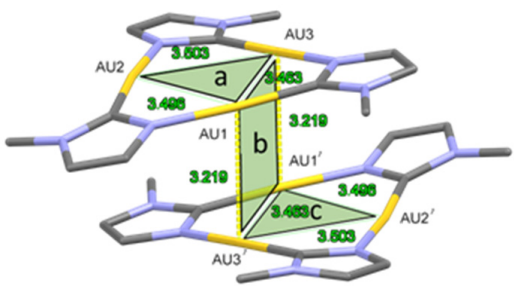

C

Figure 2. (A) A view of the molecular structure of the monomer of $\mathrm{Au}_{3}(\mathrm{MeIm})_{3}$ from solvatomorph $\beta$ with displacement ellipsoids shown at 50\% probability. Hydrogen atoms are omitted for clarity. (note that the monomer triangle molecules are identical in both polymorphs. See Figure S9). (B) Overview of the different non-covalent interactions around $\mathrm{Au}_{3}(\mathrm{MeIm})_{3}$ molecule within dimeric structure in solvatomorph $\beta$ as determined by Hirshfeld surface analysis. (Note: Due to reasons of clarity not all symmetry equivalent interactions are depicted in the figure). (C) Dimer-of-trimer formation found in

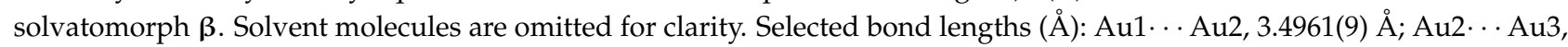

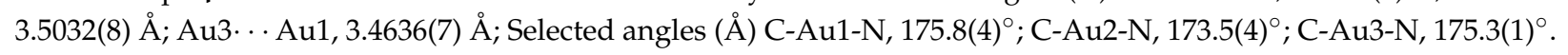

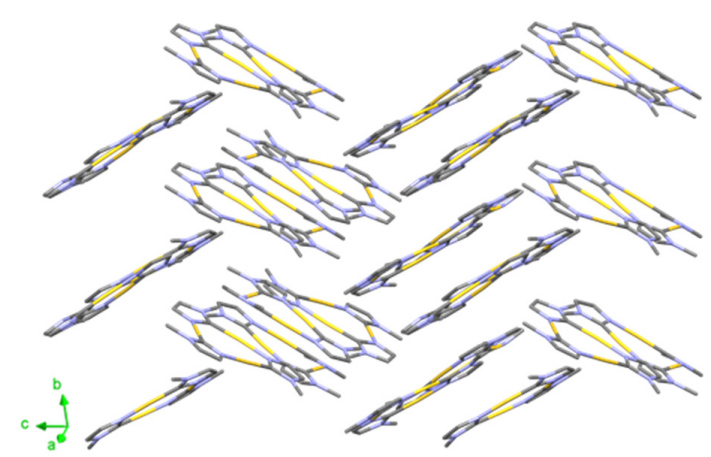

A

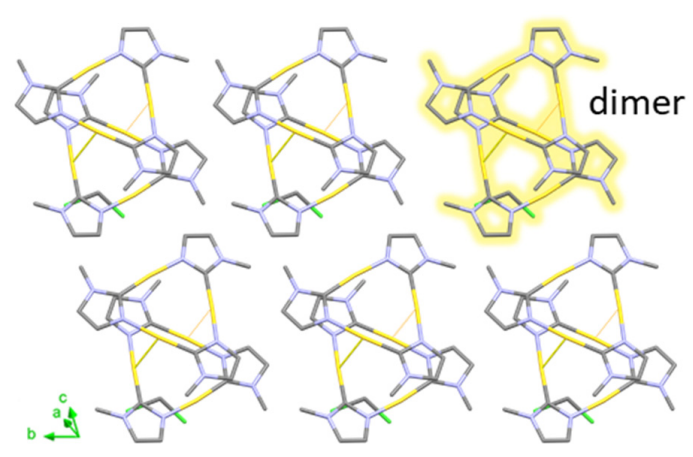

B

Figure 3. Packing of the different polymorphs of $\mathrm{Au}_{3}(\mathrm{MeIm})_{3}$ in the solid-state: (A) Solvent-free polymorph $\alpha$. (B) Solvatomorph $\beta$ (dichloromethane solvate). Hydrogen atoms were omitted for clarity.

\subsection{DFT Studies}

The results of the SCXRD analysis of solvatomorph $\beta$ together with the conducted Hirshfeld analysis clearly point towards the formation of intermolecular (additionally to coordination induced intramolecular) metallophilic $\mathrm{Au}-\mathrm{Au}$ interactions in $\mathrm{Au}_{3}(\mathrm{MeIm})_{3}$ trimer structures, which has never been observed so far. Therefore, to further rationalize the potential M-M interactions of the selected CTC, we performed electronic structure calculations by density functional theory (DFT), using the M06 meta-hybrid functional by Truhlar [35] and the CEP-31G(d) basis set [36]. This approach has successfully been applied in the theoretical description of CTCs $[37,38]$ and other systems with predominantly noncovalent interactions [39]. Specifically, Galassi and co-workers used M06/CEP-31G(d) DFT computations to examine $\mathrm{d}^{10}-\mathrm{d}^{10}$ metal-metal bonding in the aforementioned CTC, $\left[\mathrm{Au}_{2}\left(\mu-\mathrm{C}^{2}, \mathrm{~N}^{3}-\mathrm{MeIm}\right)_{2} \mathrm{Cu}\left(\mu-3,5-\left(\mathrm{CF}_{3}\right)_{2} \mathrm{Pz}\right)\right]$, which renders a direct comparison to related systems possible $[37,40]$. 
To study M-M interactions in solvatomorph $\beta$, the molecular structures of a monomeric and a dimeric CTC species were first optimized starting from the available crystallographic data. All optimized geometries were checked to be local minima of the potential energy surface (PES) by the absence of negative eigenfrequencies. The so obtained molecular structures are in good accordance with the crystallographic structures (Table 1). Lateral shifts of monomer in the computed dimeric structure are in excellent accordance with the monomer alignment found in the crystal structure.

Table 1. Comparison of calculated results from density functional theory (DFT) and experimental data from SC-XRD.

\begin{tabular}{|c|c|c|}
\hline & Experimental Data & Calculated Results \\
\hline Au-N bond $/ \AA$ & $2.030(9), 2.036(9), 2.043(8)$ & 2.091 \\
\hline $\mathrm{Au}-\mathrm{C}_{\mathrm{carb}}$ bond $/ \AA$ & $1.986(11), 1.987(11), 1.988(11)$ & 2.038 \\
\hline $\mathrm{C}_{\text {carb }}-\mathrm{Au}-\mathrm{N}$ angle $/{ }^{\circ}$ & $173.6(4), 175.3(4), 175.8(4)$ & 175.13 \\
\hline intratrimer $\mathrm{Au} 1-\mathrm{Au} 2 / \AA$ & $3.4961(9)$ & 3.567 \\
\hline intratrimer Au1-Au3/ $\AA$ & $3.4636(7)$ & 3.555 \\
\hline intratrimer $\mathrm{Au} 2-\mathrm{Au} 3 / \AA$ & $3.5032(8)$ & 3.584 \\
\hline
\end{tabular}

Based on the optimized molecular geometries, we then accessed the nature of intraand intermolecular aurophilic $\mathrm{Au}-\mathrm{Au}$ interactions by following three methodologies: (i) calculation of the Gibbs free energy of the $\mathrm{Au}_{3}(\mathrm{MeIm})_{3}$ dimer formation $\Delta G_{f}$, (ii) PES scan calculations to access the dimer dissociation energy $D_{e}$, and finally (iii) bonding order (BO) analysis by calculations of different bond orders (among others Wiberg bond order $=$ WBO [41], Mayer bond order $=$ MBO [42], Fuzzy atom bond order = FBO [43] and assessment of bond critical points $=\mathrm{BCP})$.

The HOMO of $\mathrm{Au}_{3}(\mathrm{MeIm})_{3}$ is almost exclusively localized at the three imidazolate ligands with partial contribution from the gold atoms $\left(\mathrm{p}_{\pi}\right.$-orbitals of the NHC ring and $\mathrm{d}_{\mathrm{xy}}$ orbitals of the $\mathrm{Au}(\mathrm{I})$ atoms), whereas its LUMO shows strong contributions from the gold atoms with scarcely participation of the NHC ligands (Figure S1). The HOMO-LUMO gap accounts to $0.185 \mathrm{eV}$. For $\mathrm{Au}_{3}(\mathrm{MeIm})_{3}-\{$ Dimer $\}$, the HOMO shows a strong metal contribution, however with no pronounced electron density in intermolecular bonding regions. The LUMO of $\mathrm{Au}_{3}(\mathrm{MeIm})_{3}-\{$ Dimer $\}$ reveals strong metal contributions, but with partial electron density located between two fragments, which suggests that intermolecular bonding might become stronger during photoexcitation (Figure S2). The dimer HOMO-LUMO gap accounts to $0.204 \mathrm{eV}$, as the $\mathrm{HOMO}$ level is lowered by $17.0 \mathrm{meV}$ upon aggregation.

ESP analysis of $\mathrm{Au}_{3}(\mathrm{MeIm})_{3}-\{$ Monomer $\}$ revealed a couple of minima and maxima at the electrostatic potential surface of the monomer species in ranges of $-31.2 \mathrm{kcal} / \mathrm{mol}$ to $25.1 \mathrm{kcal} / \mathrm{mol}$. The positions of these maxima are predominantly located at the hydrogen positions of the imidazolate backbone and the methyl substituent, with a global maximum found at the $\mathrm{H} 11$ position (Figure S3a). The global minima positions are mainly arising from abundant electron density below and above the positively charged $\mathrm{Au}_{3}$ triangle (Figure S3c). Assuming that only electrostatic interactions between monomers in $\mathrm{Au}_{3}(\mathrm{MeIm})_{3}-\{\mathrm{Dimer}\}$ would govern the dimer formation, a T-shaped arrangement (enabling ideal contacts of regions of high and low ESP) would be expected. However, such behaviour is apparently not found in the dimer structure of $\beta$, which excludes strong electrostatic driven interactions between monomers of $\mathrm{Au}_{3}(\mathrm{MeIm})_{3}$-\{Dimer $\}$ being structurally decisive during crystallization, which is in agreement with the literature $[10,38]$.

We further assessed $\mathrm{Au}$-Au interactions in the dimer species by calculation of $\Delta G_{f}$ and $D_{e}$. The Gibbs free energy of formation was accessed via calculations of heats of formation following the reaction equation:

$$
2 \mathrm{Au}_{3}(\mathrm{MeIm})_{3}-\{\text { Monomer }\} \rightarrow \mathrm{Au}_{3}(\mathrm{MeIm})_{3}-\{\text { Dimer }\}
$$


By doing so we found a value for the dimer interaction energy $\Delta G_{f}=-20.48 \mathrm{kcal} / \mathrm{mol}$, which is in the range expected for strong intermolecular aurophilic interactions $(-10.24 \mathrm{kcal} / \mathrm{mol}$ per Au-Au bond) [8,44] and was recently found for comparable CTCs [37,38].

To get access to the dimer dissociation energy $D_{e}$ PES scans along with the Au$\mathrm{Au}$ distance in $\mathrm{Au}_{3}(\mathrm{MeIm})_{3}-\{$ Dimer $\}$ (single point $=$ SP calculations on vertically shifted $\mathrm{Au}_{3}(\mathrm{MeIm})_{3}-\{$ Monomer $\}$ at similar level of theory, see Figure 4). Analysis of the so obtained PES revealed a $D_{e}$ of $9023 \mathrm{~cm}^{-1}$ or $26.3 \mathrm{kcal} / \mathrm{mol}$, giving rise of $13.15 \mathrm{kcal} / \mathrm{mol}$ per intermolecular $\mathrm{Au}-\mathrm{Au}$ bond. Such values are again expected for metallophilic $\mathrm{Au}-\mathrm{Au}$ interactions and are consistent with the calculated $\Delta G_{f}$.

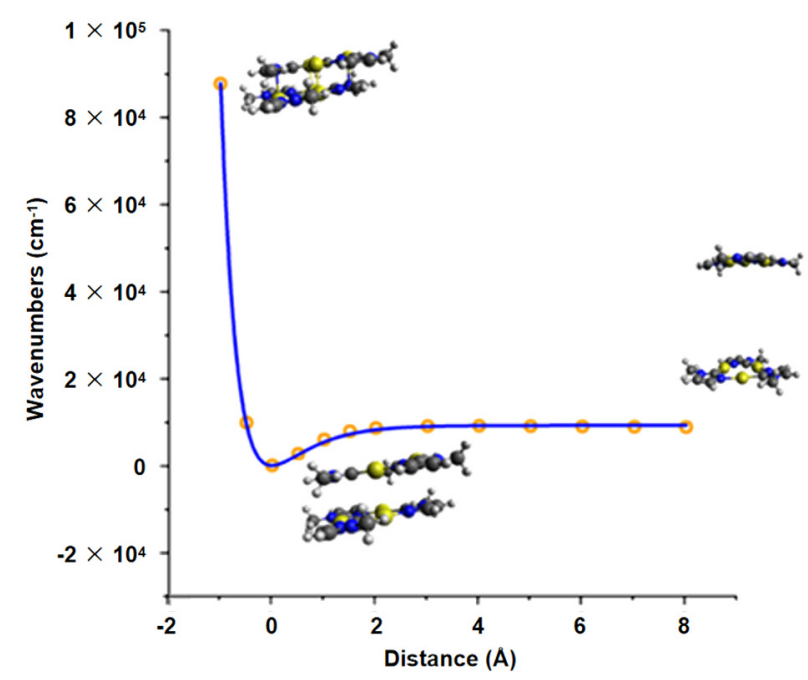

Figure 4. Results of the PES scan of the distance between two $\mathrm{Au}_{3}(\mathrm{MeIm})_{3}-\{\mathrm{Monomer}\}$ in $\mathrm{Au}_{3}(\mathrm{MeIm})_{3}-\{$ Dimer $\}$. The inset shows three structures $(-1 \AA, 0 \AA$ and $8 \AA$ ) at different distances. Note that we fitted a Morse potential to the single scan points for the extraction of $D_{e}$ (Orange circle: electronic energies from SP-DFT; blue line: fitting curve with function $\mathrm{D}_{\mathrm{e}}\left(1-\exp \left(\mathrm{a}\left(\mathrm{r}-\mathrm{R}_{\mathrm{e}}\right)\right)\right)^{2}$ and $R^{2}=0.99976$; the $R_{e}$ value was set to 0 and the energies were corrected by the lowest energy structure).

We finally calculated a number of different BOs, which are summarized in Table 2, distinguishing between $\mathrm{Au}-\mathrm{Au}$ interactions within $\mathrm{Au}_{3}(\mathrm{MeIm})_{3}-\{$ Monomer $\}$ and between $\mathrm{Au}_{3}(\mathrm{MeIm})_{3}-\{$ Monomer $\}$ in the dimeric species (labeling according to crystallographic information). Based on purely crystallographic arguments, one would assume that aurophilic interactions between monomers are more pronounced, as bonding distances are smaller than those within a monomer complex (by polymorph $\alpha 0.3 \AA$ ). Hirshfeld analysis supports this argument, as the conducted $\mathrm{BO}$ analysis does. One clearly finds, that throughout all calculated indexes the BOs are doubled when going from intra- to intermolecular $\mathrm{Au}-\mathrm{Au}$ interactions, evidencing a stronger intermolecular metallophilic binding in $\mathrm{Au}_{3}(\mathrm{MeIm})_{3}-\{$ Dimer\}. Consequently, the calculated $\mathrm{BO}$ indexes suggest appreciable metallophilic interactions to be responsible for dimer formation. (Note that the calculated $\mathrm{BO}$ values are in good agreement with literature values $[8,45])$.

Table 2. Results of the $\mathrm{BO}$ analysis showing the results of different bonding indexes (WBO = Wiber bonding order, $\mathrm{MBO}=$ Mayer bonding order, $\mathrm{FBO}=$ Fuzzy bonding order, $\mathrm{BCP}=$ bond critical point).

\begin{tabular}{ccccc}
\hline & WBO & MBO & FBO & BCP \\
\hline Au1-Au2 (intra) & 0.135 & 0.062 & 0.190 & no \\
Au1-Au3 (intra) & 0.135 & 0.079 & 0.192 & no \\
Au1-Au2-Au3 (intra) & - & 0.035 & - & yes \\
Au1-Au3 (inter) & 0.269 & (normalized multi-center BO) & 0.156 & yes \\
\hline
\end{tabular}


In closing the theoretical section, all the above-presented results attest to the fact, that in $\mathrm{Au}_{3}(\mathrm{MeIm})_{3}-\{$ Dimer $\}$ interactions between monomer species $\mathrm{Au}_{3}(\mathrm{MeIm})_{3}-\{$ Monomer $\}$ are driven by robust aurophilic $\mathrm{M}-\mathrm{M}$ interactions in accordance with the crystallographic analysis. Calculations of the dimer formation free energy underpinned by the dimer dissociation energy from PES scans, reveal rather strong aurophilic bonding interactions. Analysis of the bonding situation by different bonding indexes throughout reveals no negligible $\mathrm{BOs}$, with a rather small bonding interaction within the $\mathrm{Au}_{3}{ }^{3+}$-core, but stronger interactions between monomer complexes in the dimer.

The aurophilic interactions are commonly associated with the luminescence properties of CTCs. Given that two different metal-metal bonding interactions can be found in the solid-state of $\mathrm{Au}_{3}(\mathrm{MeIm})_{3}$, a thorough photophysical study in combination with phase analysis was conducted, to correctly correlate the photophysical active phase of the bulk material.

\subsection{Qualitative Phase Analysis and Photophysical Studies}

In the attempts to grow samples for single-crystal $X$-ray diffraction analysis, two crystallization methods were employed: (i) slow evaporation of dichloromethane solution of $\mathrm{Au}_{3}(\mathrm{MeIm})_{3}$; (ii) vapor diffusion of $n$-hexane or diethyl ether into dichloromethane solution of $\mathrm{Au}_{3}(\mathrm{MeIm})_{3}$. Additionally, crystallization experiments were carried out at different temperatures to prevent decomposition. Limited to the low diffusion coefficient of solvent at ultra-low temperature, vapor diffusion crystallization experiments with dichloromethane and hexane at $193 \mathrm{~K}$ did not yield suitable single crystals, while the slow evaporation of dichloromethane solution serendipitously offered a small number of single crystals of solvatomorph $\beta$. When applying temperates higher than $253 \mathrm{~K}\left(-20{ }^{\circ} \mathrm{C}\right)$ polymorph $\alpha$ is always yielded. Interestingly, dissolution of a solid sample of solvatomorph $\beta$ in dichloromethane followed by evaporation higher than $253 \mathrm{~K}$ also leads to the formation of the $\alpha$ polymorph.

As the preparation of bulk crystalline samples for luminescence tests is generally conducted at ambient conditions, the formation of the $\alpha$ polymorph should be expected. However, since also different solvent combinations were used, compared to the preparations of the single crystals, we carefully investigated the solid-state phase of the prepared bulk samples by means of powder X-ray diffraction (PXRD). Hereby, products from (1) fast evaporation of $\mathrm{Au}_{3}(\mathrm{MeIm})_{3}$ from a DCM/THF solution and (2) precipitation of $\mathrm{Au}_{3}(\mathrm{MeIm})_{3}$ with $n$-hexane $/ \mathrm{Et}_{2} \mathrm{O}$ from DCM/THF solution were characterized. The powder diffractograms of the samples of the two crystallization methods are shown in Figure 5A. Small differences can be visually observed (marked by asterisks), which we tentatively attribute to a minor side phase we cannot further specify. Pawley analysis was conducted on the measured powder data. The obtained cell parameters are in excellent agreement with the data from SC-XRD structures of polymorph $\alpha$ (Figure 5B). Consequently, all bulk crystallization methods at ambient conditions led to the formation of polymorph $\alpha$, and fast crystallization by solvent removal was identified to yield excellent phase-pure material according to PXRD measurements, which consequently was used in the luminescence measurements described below.

The luminescence measurement of the crystalline sampe with polymorph $\alpha$ partially fits with previously reported results by Ruiz et al. When our sample is excited at $256 \mathrm{~nm} \mathrm{UV}$ light, polymorph $\alpha$ exhibits an emission maximum at around $710 \mathrm{~nm}$ at room temperature. However, in their original work, Ruiz and co-workers report two emission bands, centered at $722 \mathrm{~nm}$ and $810 \mathrm{~nm}$. With regard to our initial results in yielding phase-pure materials of polymorph $\alpha$ (compare above), our findings point toward the fact, that the $810 \mathrm{~nm}$ band in the originally reported samples might originate from contamination of a possible side phase, potentially exhibiting stronger aurophilic contacts. In all our experiments, we were not able to reproduce bulk materials showing the emission band at $810 \mathrm{~nm}$. (Note that we were confirming phase-purity for all our samples by PXRD measurements before emission measurements, which was apparently not undertaken by Ruiz et al.) Finally, these results 
show, that a careful evaluation of bulk samples is of utter importance, when molecular properties are to be deduced from solid-state measurements.

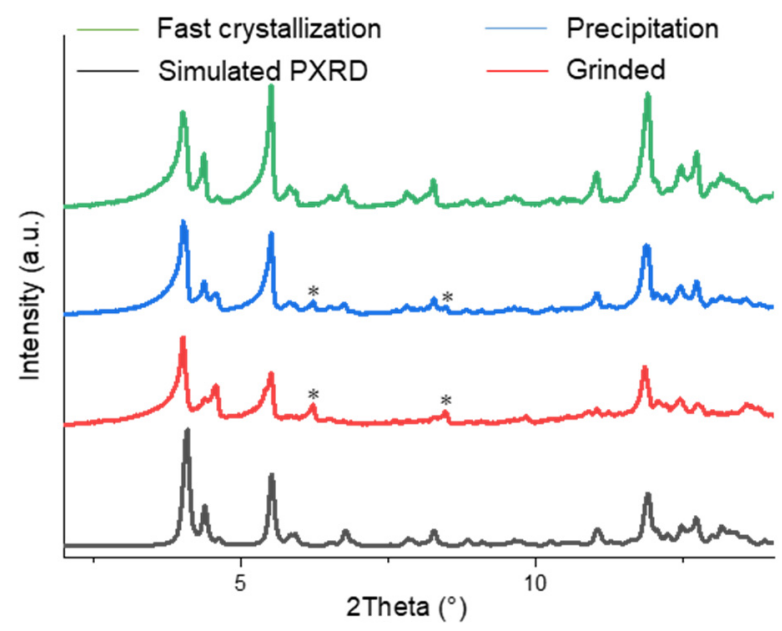

A

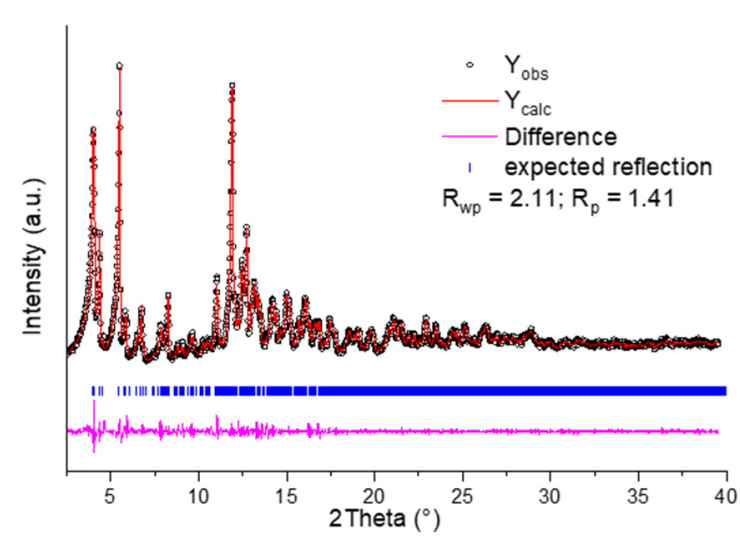

B

Figure 5. (A) Powder diffractograms $(\lambda=0.7093 \AA$ ) measured of samples obtained after fast crystallization (green), precipitation (blue), and grinded powder (red) at ambient conditions. A simulated pattern was generated from SC-XRD of polymorph $\alpha$ (black). (B) Pawley fit analysis of fast crystallization powder and calculated data. Observed data sets and calculated data are shown in black symbols and red line, respectively. The pink line shows the difference curve, while the blue marks show Bragg positions.

During the course of the photophysical study, another attractive behavior of polymorph $\alpha$ was observed when cooling the sample with liquid nitrogen. At $77 \mathrm{~K}$, the emission maximum moves to $510 \mathrm{~nm}$ with a dramatic intensity increase (quantum yield increased from $15 \%$ to $60 \%$ ) (Figure 6). When warming up to $297 \mathrm{~K}$, the original emission is restored and the whole process is fully reversible. Such a drastic hypsochromic shift at cryogenic temperature has already been observed for CTCs $[3,46,47]$. Raithby et al. considered a crystallographic phase transition as the possible origin in the temperature dependent luminescence shifts [48]. Therefore, we investigated possible structural changes or phase transitions with changing temperature. For the determination of the unit cell parameters at different temperatures, SC-XRD measurements were conducted first, showing that the crystal structure of polymorph $\alpha$ at 296(2) K remains in the same space group $P 22_{1} / c$ with $<0.5 \%$ thermal expansion compared to when measured at $100(2) \mathrm{K}$. Accordingly, calculated crystal density decreases from 3.547 to $3.452 \mathrm{~g} / \mathrm{cm}^{3}$, when the crystal is heated from $100 \mathrm{~K}$ to $296 \mathrm{~K}$; intermolecular Au-Au distances slightly increase from $3.689 \AA, 3.751 \AA, 4.141 \AA$ to $3.776 \AA$, $3.778 \AA, 4.181 \AA$, respectively. All the intermolecular Au-Au distances significantly exceed the sum of the vdW radii of $\mathrm{Au}(3.32 \AA)$ [8], no additional aurophilic interactions could be observed at cryogenic temperature. These findings are supported by non-ambient PXRD measurements (Figure 7), which also show no change in the diffraction pattern and therefore no phase transition when continuously measured between $-180{ }^{\circ} \mathrm{C}$ and $40{ }^{\circ} \mathrm{C}$. Also, the thermal expansion of the crystal structure does not show a discontinous change in the cell volume (See ESI Figure S12), therefore also not indicating a phase transition. Hence, we think that the minor structural changes in the packing of polymorph $\alpha$ cannot be correlated with the observed distinct thermochromism.

Another possible explanation for the thermochromism in CTCs have been hypothesized, e.g., by Omary and coworkers who observed similar thermochromism for $\mathrm{Au}_{3} \mathrm{EtIm}_{3}$ [3,37]. In detail, the related emission band centered at $425 \mathrm{~nm}$ at $\mathrm{T}<200 \mathrm{~K}$ shifts to $700 \mathrm{~nm}$ at $\mathrm{T} \geq 200 \mathrm{~K}$. They suggested that at a higher temperature (above $200 \mathrm{~K}$ ), a non-radiative relaxation to an intermediate excitation state takes place, which then gives rise to the low energy emission band. At lower temperatures $(\mathrm{T}<200 \mathrm{~K})$ emission from an energetically higher excitation state is supposed to happen, leading to the observed band 
centered at $425 \mathrm{~nm}$. Since we did not see any significant structural changes in the solidstate at low temperatures, this might also serve as a viable explanation of our observations for $\mathrm{Au}_{3}(\mathrm{MeIm})_{3}$.

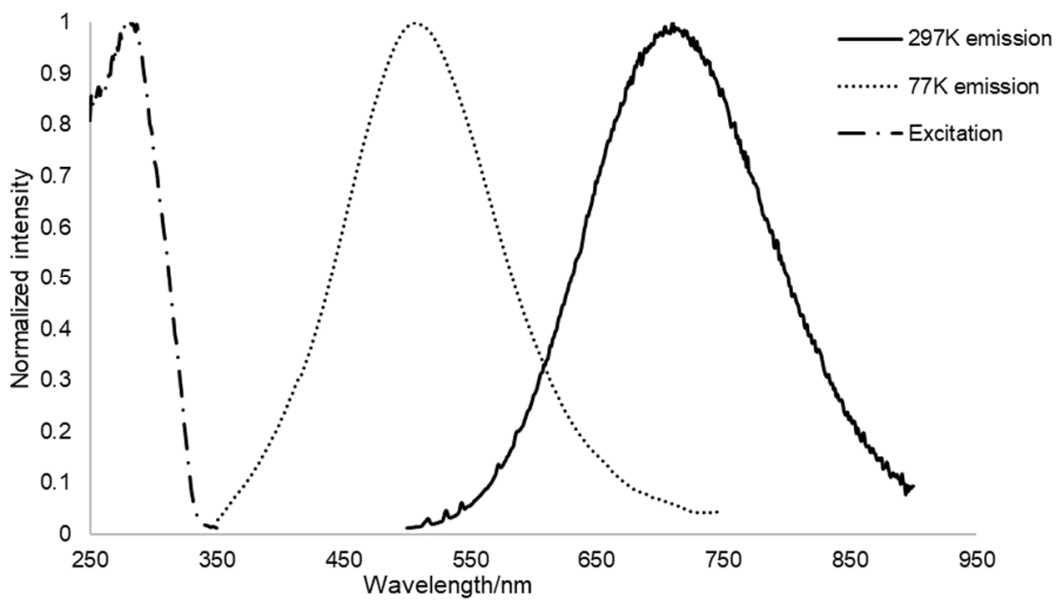

Figure 6. Diffuse reflectance and emission spectra of the solid samples of polymorph $\alpha$ at $297 \mathrm{~K}$ and $77 \mathrm{~K}$. The excitation pattern is the same at room temperature and cryogenic temperature. Excitation peak centers at $256 \mathrm{~nm}$, emission peak centers at $510 \mathrm{~nm}$ at $77 \mathrm{~K}$, emission peak centers at $710 \mathrm{~nm}$ at $297 \mathrm{~K}$. Quantum yield is $15 \%$ at $297 \mathrm{~K}$ and $60 \%$ at $77 \mathrm{~K}$, respectively. The spectra have been normalized to 1 due to reasons of comparability.

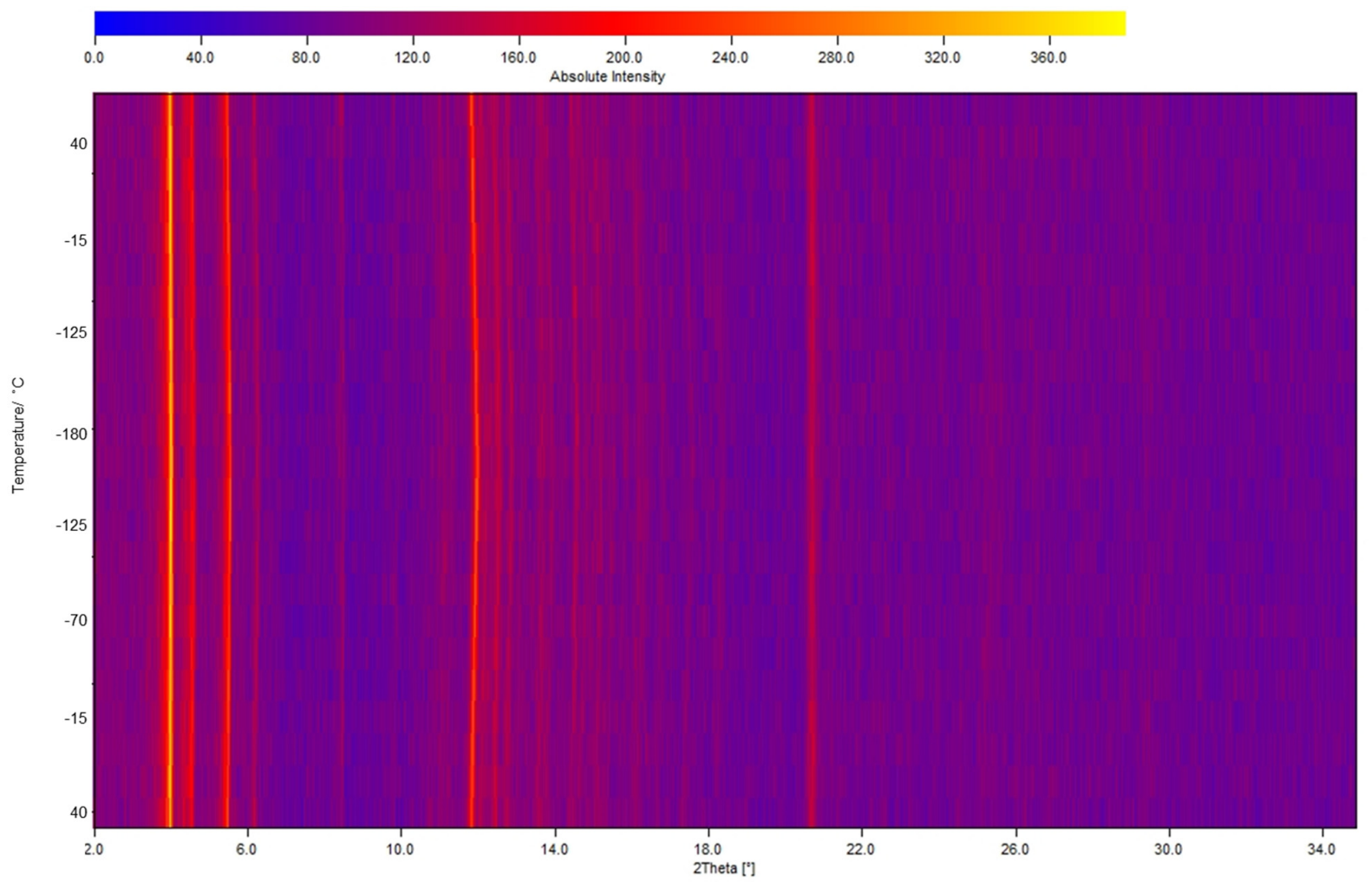

Figure 7. 3D graphic illustration of the powder XRD VT series $(\lambda=0.7093 \AA)$, the temperature goes from $40{ }^{\circ} \mathrm{C}$ to $-180{ }^{\circ} \mathrm{C}$ and back to $40{ }^{\circ} \mathrm{C}$.

\section{Materials and Methods}

All manipulations were carried out under an inert atmosphere of argon using standard Schlenk line. The preparation of $\mathrm{Au}_{3}(\mathrm{MeIm})_{3}$ followed the route described previously by Burini [7] and Vaughan [30] with minor modifications: The 1-methylimidazole was freshly 
distilled and degassed before use. Hexane and THF were dried using a MBraun MBSPS 5 apparatus and stored over $4 \AA$ molecular sieves. All other reagents were used as supplied. NMR spectra were recorded on a Bruker AV400 spectrometer at room temperature. ${ }^{1} \mathrm{H}$ NMR spectra were referenced to the signals of $\mathrm{CDCl}_{3} .2 \mathrm{mg}$ of 1-methylimidazole was dissolved in tetrahydrofuran, then cooled to $-30{ }^{\circ} \mathrm{C}$. To the stirred solution of methylimidazole in tetrahydrofuran, one equivalent of n-butyllithium in hexane was added drop-wisely under argon. The pale-yellow mixture was kept stirring for $1.5 \mathrm{~h}$ at $-30^{\circ} \mathrm{C}$, before the addition of the equal equivalent amount of chloro(tetrahydrothiophene)gold(I) in $5 \mathrm{~mL}$ tetrahydrofuran. The reaction was kept at $-30^{\circ} \mathrm{C}$ for another hour, then $0.5 \mathrm{~mL}$ of dry methanol was added to quench the reaction. Afterward, the mixture was evaporated to dryness at $0{ }^{\circ} \mathrm{C}$. The precise temperature control and anaerobic condition are obligatory for the deprotonation and metalation to happen. The remaining solid was dissolved in dichloromethane then filtered with Celite. Recrystallization in dichloromethane offered the analytical product. ${ }^{1} \mathrm{H}$ NMR $\left(400.13 \mathrm{MHz}, \mathrm{CDCl}_{3}, 298 \mathrm{~K}\right): \delta(\mathrm{ppm})=7.15(\mathrm{~s}, 3 \mathrm{H}$, $\left.\left.H_{\mathrm{NCHC}}\right), 6.96\left(\mathrm{~s}, 3 \mathrm{H}, H_{\mathrm{NCHC}}\right), 3.81\left(\mathrm{~s}, 9 \mathrm{H}, \mathrm{H}_{\mathrm{CH} 3}\right) .{ }^{13} \mathrm{C}_{\{}{ }^{1} \mathrm{H}\right\} \mathrm{NMR}\left(100.62 \mathrm{MHz}, \mathrm{CDCl}_{3}, 298\right.$ $\mathrm{K}): \delta(\mathrm{ppm})=168.51,127.67,119.89$, 35.97. ESI-MS $(\mathrm{m} / z): 834.60[\mathrm{Au} 3(\mathrm{MeIm}) 3]^{+}, 917.10$ [Au3(MeIm)3] MeIm ${ }^{+}, 1471.09$ [Au3(MeIm)3][ $\left.\mathrm{Au}_{2} \mathrm{MeIm}_{3}\right]^{+}$. Elemental analysis: Calculated for $\mathrm{C}_{12} \mathrm{H}_{15} \mathrm{Au}_{3} \mathrm{~N}_{6}$ : C, 17.28; H, 1.81; $\mathrm{Au}, 70.83 ; \mathrm{N}, 10.07$. Found: $\mathrm{C}, 17.36 ; \mathrm{H}, 1.87 ; \mathrm{N}, 9.77$. UV-Vis (solid-state, nm): 222, 259, 276.

\section{Conclusions}

In conclusion, this study revealed a new solvatomorph $\beta$ (dichloromethane solvate) of $\mathrm{Au}_{3}(\mathrm{MeIm})_{3}$, the archetypal imidazolate CTC molecule, exhibiting unprecedented short intermolecular aurophilic interactions in the solid-state which were rationalized with DFT calculations. Crystallization conditions were investigated in combination with powder X-ray diffraction monitoring to correctly correlate the photophysically active phase of bulk crystalline material. All investigated powder samples accessed via different preparation methods can be assigned to the pristine solvent-free polymorph $\alpha$, showing no aurophilic interactions. In addition, a strong thermochromic behavior of polymorph $\alpha$ was observed, going along with no significant structural changes in the solid state at low temperatures. This indicates, that the observed thermochromism might be originating from a change in the effective emission pathways of the molecular $\mathrm{Au}_{3}(\mathrm{MeIm})_{3}$ rather than emerging from a phase transition alongside with change in the intermolecular interactions. From a more generalized perspective, this study provides the first example of solvatomorphism induced aurophilic interactions in cyclic trinuclear complexes, and underlines the importance of a thorough solid-state characterization when deducing properties of molecular materials.

Supplementary Materials: The following are available online. Details on: DFT calculations, singlecrystal X-ray determinations, Hirshfeld surface analyses, and spectroscopic measurements.

Author Contributions: Investigation, S.G.; DFT, D.C.M.; luminescent measurement, S.G.\& S.J.W.; X-ray crystallography, C.J.; writing-original draft preparation, S.G.; writing-review and editing, A.C. \& A.P.; supervision, A.C. \& A.P.; project administration, A.C. \& A.P.; funding acquisition, A.C. \& A.P. All authors have read and agreed to the published version of the manuscript.

Funding: The CRC: the TUM Department of Chemistry, the Leibniz Supercomputing Centre of the Bavarian Academy of Sciences and Humanities, the Fonds der Chemischen Industrie (FCISachkostenzuschuss) and the Leonhard-Lorenz-Stiftung are very much acknowledged for funding this work. S.G. thanks the Chinese Research Council for a personal scholarship as well as Prof. Angela Casini for mentorship and support. S.G., D.C.M, and S.J.W. thank the TUM GS for financial support. We also thank the Leibniz Supercomputing Centre of the Bavarian Academy of Sciences and Humanities for provision of computational time.

Institutional Review Board Statement: Not applicable.

Informed Consent Statement: Not applicable. 
Data Availability Statement: CCDC 2093115-2093117 contain the supplementary crystallographic data for this paper. These data can be obtained free of charge from The Cambridge Crystallographic Data Centre via www.ccdc.cam.ac.uk/structures.

Acknowledgments: S.G. is grateful to the China Scholarship Council (CSC) and TUM-GS for the financial support. We thank Leibniz Computing Center for high performance computational time.

Conflicts of Interest: The authors declare no conflict of interest.

Sample Availability: Samples are not available from the authors.

\section{References}

1. Gimeno, M.C.; Johnson, A. Yldiide Ligands as Building Blocks for Polynuclear Coinage Metal Complexes: Metal Squares, Triangles and Chains. Chem. A Eur. J. 2020, 26, 11256-11265. [CrossRef] [PubMed]

2. Gade, L.H. "Hyt was of Gold, and Shon so Bryghte ... ": Luminescent Gold (I) Compounds. Angew. Chem. Int. Ed. Engl. 1997, 36, 1171-1173. [CrossRef]

3. Ghimire, M.M.; Nesterov, V.N.; Omary, M.A. Remarkable aurophilicity and photoluminescence thermochromism in a homoleptic cyclic trinuclear gold (I) imidazolate complex. Inorg. Chem. 2017, 56, 12086-12089. [CrossRef]

4. Rawashdeh-Omary, M.A.; Omary, M.A.; Fackler, J.P.; Galassi, R.; Pietroni, B.R.; Burini, A. Chemistry and optoelectronic properties of stacked supramolecular entities of trinuclear gold (I) complexes sandwiching small organic acids. J. Am. Chem. Soc. 2001, 123, 9689-9691. [CrossRef] [PubMed]

5. Olmstead, M.M.; Jiang, F.; Attar, S.; Balch, A.L. Alteration of the Aurophilic Interactions in Trimeric Gold (I) Compounds through Charge Transfer. Behavior of Solvoluminescent $\mathrm{Au}_{3}(\mathrm{MeN} \mathrm{COMe})_{3}$ in the Presence of Electron Acceptors. J. Am. Chem. Soc. 2001, 123, 3260-3267. [CrossRef] [PubMed]

6. Burini, A.; Fackler, J.P., Jr.; Galassi, R.; Grant, T.A.; Omary, M.A.; Rawashdeh-Omary, M.A.; Pietroni, B.R.; Staples, R.J. Supramolecular chain assemblies formed by interaction of a $\pi$ molecular acid complex of mercury with $\pi$-base trinuclear gold complexes. $J$. Am. Chem Soc. 2000, 122, 11264-11265. [CrossRef]

7. Bonati, F.; Burini, A.; Pietroni, B.R.; Bovio, B. Reactions of C-imidazolyllithium derivatives with group Ib compounds: Tris[ $\mu$-(1alkylimidazolato-N3, C2)] tri-gold (I) and-silver (I). Crystal structure of bis (1-benzylimidazolin-2-yliden) gold (I) chloride. J. Organomet. Chem. 1989, 375, 147-160. [CrossRef]

8. Schmidbaur, H.; Schier, A. Aurophilic interactions as a subject of current research: An up-date. Chem. Soc. Rev. 2012, 41, 370-412. [CrossRef]

9. Schmidbaur, H.; Schier, A. A briefing on aurophilicity. Chem. Soc. Rev. 2008, 37, 1931-1951. [CrossRef]

10. Tekarli, S.M.; Cundari, T.R.; Omary, M.A. Rational design of macrometallocyclic trinuclear complexes with superior $\pi$-acidity and $\pi$-basicity. J. Am. Chem. Soc. 2008, 130, 1669-1675. [CrossRef]

11. Vickery, J.C.; Olmstead, M.M.; Fung, E.Y.; Balch, A.L. Solvent-Stimulated Luminescence from the Supramolecular Aggregation of a Trinuclear Gold (i) Complex that Displays Extensive Intermolecular AuċAu Interactions. Angew. Chem. Int. Ed. Engl. 1997, 36, 1179-1181. [CrossRef]

12. Hayashi, A.; Olmstead, M.M.; Attar, S.; Balch, A.L. Crystal chemistry of the Gold (I) Trimer, $\mathrm{Au}_{3}(\mathrm{NC} 5 \mathrm{H} 4)_{3}$ : Formation of hourglass figures and self-association through aurophilic attraction. J. Am. Chem. Soc. 2002, 124, 5791-5795. [CrossRef]

13. Omary, M.A.; Elbjeirami, O.; Gamage, C.S.P.; Sherman, K.M.; Dias, H.R. Sensitization of Naphthalene monomer phosphorescence in a sandwich adduct with an electron-poor trinuclear Silver (I) pyrazolate complex. Inorg. Chem. 2009, 48, 1784-1786. [CrossRef]

14. Osuga, T.; Murase, T.; Fujita, M. Triple-Decker $\mathrm{Au}_{3}-\mathrm{Ag}-\mathrm{Au}_{3}-\mathrm{Ag}-\mathrm{Au}_{3}$ Ion Cluster Enclosed in a Self-Assembled Cage. Angezw. Chem. 2012, 124, 12365-12367. [CrossRef]

15. Kiguchi, M.; Inatomi, J.; Takahashi, Y.; Tanaka, R.; Osuga, T.; Murase, T.; Fujita, M.; Tada, T.; Watanabe, S. Highly Conductive [3 $\times$ n] Gold-Ion Clusters Enclosed within Self-Assembled Cages. Angew. Chem. 2013, 125, 6322-6325. [CrossRef]

16. Osuga, T.; Murase, T.; Hoshino, M.; Fujita, M. A Tray-Shaped, PdII-Clipped $\mathrm{Au}_{3}$ Complex as a Scaffold for the Modular Assembly of $[3 \times \mathrm{n}]$ Au Ion Clusters. Angew. Chem. Int. Ed. 2014, 53, 11186-11189. [CrossRef] [PubMed]

17. Bovio, B.; Calogero, S.; Wagner, F. A study of reaction products of trimerie 1-benzyl-2-gold (I)-imidazole leading to Au^ $I$ carbene or $\mathrm{Au}$ I I imidazoline complexes and trinuclear A^^III imidazolyl derivatives X-ray crystal structure of [\{( $\mu$-1-benzylimidazolato-N3, C2) Au\} 312]. J. Organomet. Chem. 1994, 470, 275. [CrossRef]

18. Hahn, R.; Bohle, F.; Fang, W.; Walther, A.; Grimme, S.; Esser, B. Raising the Bar in Aromatic Donor-Acceptor Interactions with Cyclic Trinuclear Gold (I) Complexes as Strong $\pi$-Donors. J. Am. Chem. Soc. 2018, 140, 17932-17944. [CrossRef]

19. Burini, A.; Bravi, R.; Fackler Jr, J.P.; Galassi, R.; Grant, T.A.; Omary, M.A.; Pietroni, B.R.; Staples, R.J. Luminescent Chains Formed from Neutral, Triangular Gold Complexes Sandwiching T1I and AgI. Structures of $\left\{\mathrm{Ag}\left(\left[\mathrm{Au}\left(\mu-\mathrm{C}_{2}, \mathrm{~N}_{3}-\mathrm{bzim}\right)\right]_{3}\right)_{2}\right\} \mathrm{BF} 4 \cdot \mathrm{CH} 2 \mathrm{Cl} 2,\{\mathrm{Tl}$ $\left(\left[\mathrm{Au}\left(\mu-\mathrm{C}_{2}, \mathrm{~N}_{3} \text {-bzim) }\right]_{3}\right)_{2}\right\}$ PF6 $0.5 \mathrm{THF}$ (bzim= 1-Benzylimidazolate), and $\left\{\mathrm{Tl}\left([\mathrm{Au}(\mu-\mathrm{C}(\mathrm{OEt}) \mathrm{NC} 6 \mathrm{H} 4 \mathrm{CH} 3)]_{3}\right)_{2}\right\}$ PF6 THF, with MAu6 (M = Ag+, Tl+) Cluster Cores. Inorg. Chem. 2000, 39, 3158-3165. [PubMed]

20. Ruiz, J.; Sol, D.; Mateo, M.A.; Vivanco, M.; Badía-Laiño, R. A new approach to the synthesis of trinuclear gold (i) imidazolate complexes and their silver (i)-induced photoluminescence behavior. Dalton Trans. 2020, 49, 6561-6565. [CrossRef] 
21. Jandl, C.; Öfele, K.; Pöthig, A. A Pd Halide Cluster from 1964: Pd6Cl8 Capped by Ring-Opened C3Ph3 Ligands from Oxidative Addition of Cyclopropenium Ions. Organometallics 2017, 36, 4348-4350. [CrossRef]

22. Jandl, C.; Pankhurst, J.R.; Love, J.B.; Pöthig, A. Rational Synthesis and Electronic Structure of Functionalized Trinuclear Pd Metal Sheet Sandwich Complexes. Organometallics 2017, 36, 2772-2783. [CrossRef]

23. Altmann, P.J.; Pöthig, A. Pillarplexes: A metal-organic class of supramolecular hosts. J. Am. Chem. Soc. 2016, 138, 13171-13174. [CrossRef] [PubMed]

24. Guan, S.; Pickl, T.; Jandl, C.; Schuchmann, L.; Zhou, X.; Altmann, P.J.; Pöthig, A. Triazolate-based pillarplexes: Shape-adaptive metallocavitands via rim modification of macrocyclic ligands. Org. Chem. Front. 2021. [CrossRef]

25. Schmidbaur, H.; Graf, W.; Müller, G. Weak Intramolecular Bonding Relationships: The Conformation-Determining Attractive Interaction between Gold (I) Centers. Angew. Chem. Int. Ed. Engl. 1988, 27, 417-419. [CrossRef]

26. Davey, R.J. Polymorphism in Molecular Crystals Joel Bernstein; Oxford University Press: New York, NY, USA, 2002; Volume 2, pp. 675-676. ISBN 0198506058.

27. Lefebvre, J.; Batchelor, R.J.; Leznoff, D.B. Cu[Au(CN)2]2(DMSO)2: Golden Polymorphs That Exhibit Vapochromic Behavior. J. Am. Chem. Soc. 2004, 126, 16117-16125. [CrossRef]

28. White-Morris, R.L.; Olmstead, M.M.; Balch, A.L. Aurophilic interactions in cationic gold complexes with two isocyanide ligands. Polymorphic yellow and colorless forms of [(cyclohexyl isocyanide) 2AuI](PF6) with distinct luminescence. J. Am. Chem Soc. 2003, 125, 1033-1040. [CrossRef]

29. He, X.; Yam, V.W.-W. Luminescent gold(I) complexes for chemosensing. Coord. Chem. Rev. 2011, 255, 2111-2123. [CrossRef]

30. Vaughan, L.G. Organogold chemistry. III. 2-pyridylgold (I). J. Am. Chem. Soc. 1970, 92, 730-731. [CrossRef]

31. Spackman, M.A.; Jayatilaka, D. Hirshfeld surface analysis. CrystEngComm 2009, 11, 19-32. [CrossRef]

32. Schmidbaur, H.; Raubenheimer, H.G.; Dobrzańska, L. The gold-hydrogen bond, Au-H, and the hydrogen bond to gold, Au. . H-X. Chem. Soc. Rev. 2014, 43, 345-380. [CrossRef]

33. Kryachko, E.; Karpfen, A.; Remacle, F. Nonconventional hydrogen bonding between clusters of gold and hydrogen fluoride. J. Phys. Chem. A 2005, 109, 7309-7318. [CrossRef]

34. Rigoulet, M.; Massou, S.; Carrizo, E.D.S.; Mallet-Ladeira, S.; Amgoune, A.; Miqueu, K.; Bourissou, D. Evidence for genuine hydrogen bonding in gold (I) complexes. Proc. Natl. Acad. Sci. USA 2019, 116, 46-51. [CrossRef]

35. Zhao, Y.; Schultz, N.; Truhlar, D.G. Design of density functionals by combining the method of constraint satisfaction with parametrization for thermochemistry, thermochemical kinetics, and noncovalent interactions. J. Chem. Theory Comput. 2006, 2, 364-382.

36. Cundari, T.R.; Stevens, W.J. Effective core potential methods for the lanthanides. J. Chem. Phys. 1993, 98, 5555-5565. [CrossRef]

37. Galassi, R.; Ghimire, M.M.; Otten, B.M.; Ricci, S.; McDougald, R.N.; Almotawa, R.M.; Alhmoud, D.; Ivy, J.F.; Rawashdeh, A.-M.M.; Nesterov, V.N. Cupriphication of gold to sensitize d10-d10 metal-metal bonds and near-unity phosphorescence quantum yields. Proc. Natl. Acad. Sci. USA 2017, 114, E5042-E5051. [PubMed]

38. Galassi, R.; Ricci, S.; Burini, A.; Macchioni, A.; Rocchigiani, L.; Marmottini, F.; Tekarli, S.M.; Nesterov, V.N.; Omary, M.A. Solventless supramolecular chemistry via vapor diffusion of volatile small molecules upon a new trinuclear silver (I)-nitrated pyrazolate macrometallocyclic solid: An experimental/theoretical investigation of the dipole/quadrupole chemisorption phenomena. Inorg. Chem. 2013, 52, 14124-14137. [CrossRef]

39. Zhao, Y.; Truhlar, D.G. Density functionals with broad applicability in chemistry. Acc. Chem. Res. 2008, 41, 157-167. [CrossRef]

40. Jayaratna, N.B.; Olmstead, M.M.; Kharisov, B.I.; Dias, H.R. Coinage Metal Pyrazolates [(3, 5-(CF3) 2Pz) M] $3(\mathrm{M}=\mathrm{Au}, \mathrm{Ag}$, Cu) as Buckycatchers. Inorg. Chem. 2016, 55, 8277-8280. [CrossRef]

41. Coulson, C.A. The electronic structure of some polyenes and aromatic molecules. VII. Bonds of fractional order by the molecular orbital method. Proc. R. Soc. Lond. Ser. A Math. Phys. Sci. 1939, 169, 413-428.

42. Giambiagi, M.; Giambiagi, M.; Grempel, D.R.; Heymann, C.D. Sur la définition d'un indice de liaison (TEV) pour des bases non orthogonales. Propriétés et applications. J. Chim. Phys. 1975, 72, 15-22. [CrossRef]

43. Mayer, I.; Salvador, P. Overlap populations, bond orders and valences for 'fuzzy'atoms. Chem. Phys. Lett. 2004, 383, 368-375. [CrossRef]

44. Schmidbaur, H.; Raubenheimer, H.G. Excimer and Exciplex Formation in Gold (I) Complexes Preconditioned by Aurophilic Interactions. Angew. Chem. 2020, 59, 14748-14771. [CrossRef]

45. Vellé, A.; Rodríguez-Santiago, L.; Sodupe, M.; Sanz Miguel, P.J. Enhanced Metallophilicity in Metal-Carbene Systems: Stronger Character of Aurophilic Interactions in Solution. Chem. A Eur. J. 2020, 26, 997-1002. [CrossRef] [PubMed]

46. Yang, C.; Messerschmidt, M.; Coppens, P.; Omary, M.A. Trinuclear gold (I) triazolates: A new class of wide-band phosphors and sensors. Inorg. Chem. 2006, 45, 6592-6594. [CrossRef] [PubMed]

47. Omary, M.A.; Rawashdeh-Omary, M.A.; Gonser, M.A.; Elbjeirami, O.; Grimes, T.; Cundari, T.R.; Diyabalanage, H.V.; Gamage, C.S.P.; Dias, H.R. Metal Effect on the Supramolecular Structure, Photophysics, and Acid-Base Character of Trinuclear Pyrazolato Coinage Metal Complexes. Inorg. Chem. 2005, 44, 8200-8210. [CrossRef] [PubMed]

48. Woodall, C.H.; Christensen, J.; Skelton, J.M.; Hatcher, L.E.; Parlett, A.; Raithby, P.R.; Walsh, A.; Parker, S.C.; Beavers, C.M.; Teat, S.J. Observation of a re-entrant phase transition in the molecular complex tris ( $\mu 2-3,5$-diisopropyl-1, 2, 4-triazolato-k2N1: N2) trigold (I) under high pressure. IUCrJ 2016, 3, 367-376. [CrossRef] [PubMed] 